\title{
A production system model for Mini-Factories and last mile production approach
}

\author{
Cristiano Zanetti, Marco Seregni, Massimo Bianchini and Marco Taisch
}

\begin{abstract}
Downsizing the production system model within a urban environment represents an opportunity for re-shoring the manufacturing industry.

A strong involvement of End Users in product design and development, manufacturing and distribution is essential for traditional SMEs, which strive to find new business opportunities and to be as close as possible to their Customers.

Manufacturing systems based on a Mini-Factory approach is one of the modern pervasive production models providing tailored products with low cost and short delivery time.

After analyzing the definition and key characteristics of a Mini-Factory in literature, essentially based on contributions by Reichwald, Stotko \& Piller [1], a new production system model is proposed. Indeed, due to its peculiarities, this model has been reviewed and updated, to better reflect the challenges in the European furniture sector and to eventually extend the results to further industries.
\end{abstract}

Index Terms - Mini-Factory, Distributed Mini-factories network, Furniture

\section{INTRODUCTION}

European furniture industry marked a turnover of 95 billions of Euros in 2010, with a total of 130.000 companies, mainly consisting in local small enterprises, and 1,04 millions of employees [2]. These data highlights the great relevance of this sector for the EU economies. Furthermore, Europe plays a main role within the worldwide furniture industry for its strong influence in terms of fashion and design trends. However, the recent economic crisis, which has strongly affected Western Europe Countries since 2009, together with the increase of the global competition, caused an on-going production transfer from EU countries to low-labour cost countries. Meanwhile, customer expectations in terms of personalization degree and environmental sustainability are rapidly increasing, in particular among young and middle age people [3].

In order to cope with these challenges, European enterprises are looking to be more and more innovative in each aspect, i.e. products and manufacturing processes as well as in the organization.

Submitted on the $4^{\text {th }}$ of May 2015.

The work presented here is part of the project "CTC- Close To Customer"; this project has received funding from the European Union's Seventh Framework Programme for research, technological development and demonstration under grant agreement no FoF.NMP.2013-6 608736 CTC

C. Zanetti, M. Seregni, M. Bianchini and M. Taisch are with Politecnico di Milano, Department of Management, Economics and Industrial Engineering, Milano, Italy (e-mail: cristiano.zanetti@polimi.it, marco.seregni@polimi.it, $\quad \underline{\text { massimo.bianchini@polimi.it, }}$ marco.taisch@polimi.it)
With respect to the above-mentioned challenges, a production system based on a Mini-Factories network could be an effective solution [4], able to ensure high-personalized products while dealing with the high heterogeneity among EU local markets [5].

Within this paper 'Mini-Factory' concept refers to a smallscale production unit based on a single $\mathrm{CNC}$ machine and directly connected to a design configurator, aiming at producing customized furniture.

In the second paragraph, authors describe methodology followed for reviewing the State of the Art and building model of Mini-Factory for the furniture industry, which is presented in detail as a concept (Section III) and as a Production System Model (Section IV).

Since a greater relevance is posed to the networking of the Mini factories, in the fourth paragraph, authors briefly explore changes in the previous model brought by a second-tier organization ("Macro factory"), the role of which is providing supporting activities for a Mini-Factories network.

Finally, conclusion remarks and limitations are emphasized in order to provide starting point for future research.

\section{Methodology}

As first step, a literature review focused on "Mini-Factory" has been carried on the main scientific databases. This activity has shown that a limited number of studies on this specific topic and all of them presented a conceptual approach [4].

Secondly, authors have used three instruments in this paper for developing an operationalized model of Mini-Factory: Light case studies, survey and face-to-face interviews.

\section{A. "Light" case studies}

This instrument consists in a qualitative analysis of case studies mainly based on secondary data, mostly coming from enterprises' web page and public open documents. Due to the source of this data, they are defined "light" case studies.

The aim of this activity is to analyse and to identify common choices in manufacturing and operations management within small production systems for non-standardized products. Consequently, selection of the cases has focused on two dimensions:

- distributed production system based on small-scale and highly automatized units.

- high customization of the products sold.

The cases selection has been not limit focused mainly on the furniture enterprises, even though samples from other sectors (e.g. automotive) have been carefully analysed for their strictly similarities in terms of local supply chain and high personalized product. 


\section{B. Survey}

A specific survey targeting wooden furniture manufacturers operating in Europe has been created with the aim of collecting empirical data on how furniture manufacturers cope with challenges posed by mass customization. For this reason, this survey investigates several aspects regarding product definition and production processes organization as well as supply chain configuration.

The manufacturers' survey is divided in two questionnaires:

- one addressing the wooden manufacturers as is situation, i.e. information about their existing manufacturing approaches to answer customization issues;

- one focusing on a "what if" scenario, dealing with how interviewees would organize a small-scale production system model for high personalized furniture.

Both the questionnaires are divided into three sections:

- Product, Customization and Design, aiming at identifying furniture with a higher request of customization, most relevant customization options (e.g. finishing, accessories, etc.) as well as the resources for implementing customized production.

- Production and Supply Chain, aiming at identifying production technologies (e.g. Business software, manufacturing machinery, etc.), supply chain structure (e.g. outsourced activities, number and typologies of suppliers), layout configuration (e.g. overall surface, integration among warehouse, factory and shop, etc.) and performances to be ensured (e.g. delivery time, scraps, etc.).

- Market, mainly focused on marketing strategies regarding location, promotion, and potential customers.

The sample includes 20 Italian manufacturers operating in the wooden furniture industry, ranging from Micro-enterprises to medium size companies. Enterprises selected are localized in different contexts, such as industrial districts, urban and suburban areas.

\section{Face-to-face interview}

After the completion of the surveys, authors selected a restricted number of enterprises based on their production system as well as their product features. Aims of the

Face-to-face interviews have been conducted with them for exploring more in detail manufacturing choices and strategies, i.e. insourcing vs. outsourcing, inventory management,.

Since the majority of the enterprises were SMEs, it has been possible to directly interact with entrepreneurs, thus obtaining information on all the aspect of a

Authors used answers given by the interviewee to the above mentioned survey as beginning point for the discussion. The outcomes of all the three activities represented the knowledge grounds, i.e. best practices and performances to be ensured, on which the Mini-Factory model has been built.

\section{MINI-FACTORY CONCEPT}

Mini-Factory network represents one of the several models included in "Distributed Manufacturing" (DM) concept [6]. DM for which two different interpretations have been proposed in the last decade. The first one refers to the concept of creating value at geographically dispersed manufacturing locations of one enterprise. On the contrary, the second interpretation focuses on Distributed Manufacturing Systems (DMS), a class of manufacturing systems with multiple manufacturing units characterized by common properties: autonomy, flexibility, adaptability, agility and decentralization [7].

In 2005 Reichwald, Stotko, \& Piller defined Mini-Factory as "[...] a designed scalable, modular, geographically distributed unit that is networked with other units of this type"[1]. In their model, this production unit has to provide all the necessary operations for the completion of a customer's order:

- design with a high involvement of customer and supported by user friendly tools (e.g. configurator software);

- customized manufacturing on the basis of the customer's requests recorded in the previous phase;

- after-sales activities, i.e. delivery, maintenance, end-of-life collection and disposal and other supplementary services.

They stressed the importance of create a network of MiniFactories, with the aim of sharing various types of data (i.e. customer requirements, technological issue solutions, best practices), thus giving the opportunity to personnel to access a huge and global knowledge.

In addition, the localization near customer of this units enables the growth of repeating purchase, hence exploiting the economies of integration [8]. According to Zaeh and Wagner this distributed instantiation of Mini-Factories could also have economic returns in terms of decreased logistic costs and delivery time [9].

The previous schema consists also of a central command unit, which carries out support to the network of Mini-Factories, i.e. standardized raw materials procurement, operators' training and basic product features definition. Within a Mini-Factory, modularity means that each local unit includes modules with standard interfaces for easily combining them, thus ensuring a high changeability [10].

Finally, for a local enterprise that aims to establish itself in other countries, Mini-Factory model represents a viable opportunity for effectively implementing this transnational strategy [11].

\section{MINI-FACTORY: A NEW PRODUCTION SYSTEM MODEL}

The re-localization of manufacturing activities within urban contexts, the downsizing of production systems and the integration/hybridization among production, design and distribution, in terms of processes and locations, represent three emerging trends, which define a potential new paradigm in the field of the industrial production. In this regard, a small scale production system, properly located within a shopping mall or a Do-It-Yourself center, is able to directly interact with the customers, while being close to them in terms of design expectations, quality, environment, costs an delivery time. In addition, a recent survey by the Wall Street Journal [12] revealed that the vacancy rate is up to $8 \%$ in regional malls in United States and similar trends are expected in Europe, due to steady increase of on-line market places. This opportunity results in renting cost reduction and in an incentive to relocate 
small production centers as close as possible to the customers (i.e. CTC).

The afore mentioned survey and interviews outcomes represent the basis on which the Mini Factory production system model has been built and developed. By summarizing information provided by manufacturers, authors have been able to understand optimal configuration for Mini factory (e.g. product portfolio, supply chain structure, etc.) as well as issues and constraints to cope with, i.e. technologies, environment health and safety issues. Moreover, they provide also performances thresholds (e.g. scraps, delivery time, customization level, etc.) for being the Mini factory profitable and competitive against traditional woodworkers.

The scope of this paper is focused on woodworking MiniFactories only, even though findings might be extended to further industrial sectors, while bearing in mind regulatory, technological, operational and social constraints.

\section{A. Product definition}

To begin with, the first pillar of the Production System Model (i.e. PSM) is represented by the product definition. It is very important to take into account that furniture integrate a part of a larger and interactive customer experience, which strongly integrates design, production and distribution. Consumer involvement essentially consists in matching his requirements and technological constraints trough a parametric configurator software that both professionals and unskilled users can easily use.

In order to set up a proper design and production strategy, three main aspects have to be considered, i.e. product logic, product system/portfolio and customization.

As far as product logic is regarded, three main criteria should be adopted:

- pieces of furniture should be flat-pack based, ready to be assembled and easy to be disassembled;

- packaging consumable and instructions shall be included;

- common kinds of wooden panels: (laminated) chipboard, (laminated) plywood and (varnished) MDF should be used only.

A wide range of formats and special finishing are available on the market, e.g. fireproof and waterproof panels. Other materials such as composites and polymers (e.g. PMMA) can be also directly cut using CTC woodworking machine. Instead, the local suppliers could provide other materials such as metals, marble and glasses upon request.

With regards to product system/portfolio the research scope has been limited to living rooms and children bedrooms, which represent general purpose environment. Further products may be developed on occurrence, bearing in mind relevant product/process requirements and constraints.

A robust scientific literature has explored the relationship between design and mass customization, thus highlighting the need for special attention on both the product structure and the product aesthetics [13]. These have been reflected into two general design rules, which are based on the maximum reduction of hardware and the design of new standard parts and components facilitating the development of modular furniture. Both trends could lead to a 'smarter' influence on the Mini-Factory production system model, reducing the warehouse surface and complexity, while meeting the customers' expectations.

\section{B. Operations Management}

The second pillar of the 'Mini-Factory' mainly consists in the operations management. A Mini-Factory is both a production unit and a distribution and contact point, which provides finished products to the customers without intermediaries. Hence, CTC Mini-Factory is divided into two areas, i.e. "the Shop" and "the Factory.

Its PSM has been conceived as a single CNC machine, directly connected to a design configurator, aiming at producing customized furniture. Both upstream and downstream processes have been taken into account, as depicted on figure 1 functional schema.

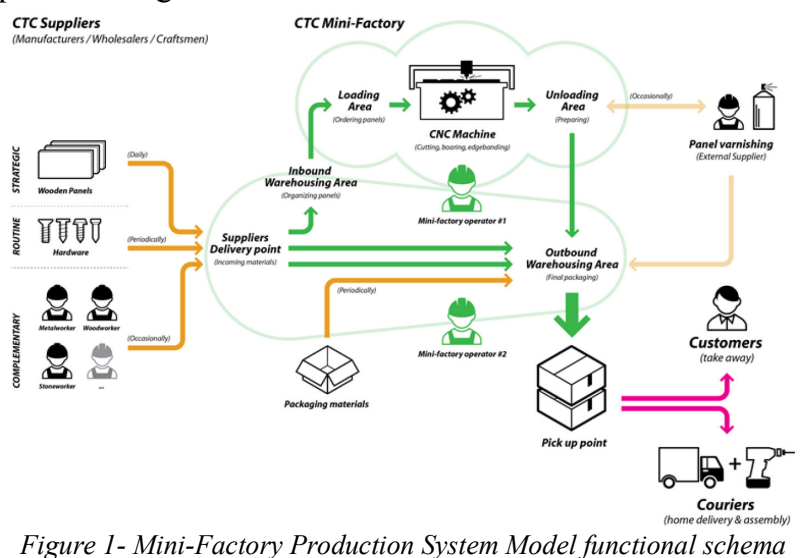

Suppliers' network is essentially a set of woodworkers, wholesalers and artisans, who work in cooperation with the Mini-Factory, thus providing raw materials and consumables. They have been classified in three categories on the basis of the purchase volume and customization required:

- Strategic: High volume and High Customization (e.g. wooden panels)

- Routine: High volume and Low Customization (e.g. hardware parts and components supplier);

- Complementary: Low volume, high customization (e.g. Iron Workers, Glass Workers, etc.).

As far as strategic suppliers are concerned standardization of purchased panels is essential to reduce the management complexity and not-value-added storing areas. A "pre-nesting" activity has to be performed, thus heuristically establishing panels mix for manufacturing a specific piece of furniture. By analyzing the local panel markets, the highest range of products are usually guaranteed by wholesaler within 24-48 hours, thus limiting inventory.

Routine suppliers typically deliver hardware and components, which are referred to as joints, brackets, fitting and accessories. The favorite procurement strategy is based on on-gong replenishment policies, such as on-line delivery or consignment stock, providing that an agreement can be 
reached with a large manufacturer/wholesaler.

Complementary suppliers (e.g. Iron Workers, Glass Workers, Decorators, Marble workers, etc.) provide those materials are can be integrated into the piece of furniture, thus meeting specific customers' demands on occurrence. The following complementary suppliers have been identified:

Since these raw materials are not standardized, a purchaseon-demand policy should be pursued, to reduce space renting costs and obsolescence. In terms of location, interviews with the Woodworkers showed that it is preferable to rely on local Suppliers, to reduce time to market and to enable tailored solutions.

Mini-Factory operations include all the activities necessary to manufacture finished and pre-packed furniture components, starting from standard panels and consumables.

A single general purpose $\mathrm{CNC}$ machine, served by an anthropomorphic robot, is capable of performing a whole series of tasks, such as cutting, boring, edge banding and nesting, in order to transform wooden panels into pieces of furniture. The operator should be monitoring the whole process and he should be assigned the following specific tasks: sorting out, loading and positioning the stack of panels in front of the machine, packaging the pieces of furniture after machining into a cardboard box.

Bearing in mind that long term production planning is difficult to achieve for a Mini-Factory, production scheduling deals with a design-to-order (i.e. DTO) approach, which is essentially based on two key decisions:

1. Assignment Problem (Routing): timed assignment of production orders to machines according to their availability (not necessary for a stand-alone machine);

2. Production sorting (Sequencing): definition of the orders processing sequences on the basis of priority criteria.

The objective of the scheduling process within a Mini-Factory is therefore to avoid delays and to minimize production swarfs. The latter represents a challenge and it has been furtherly analyzed, to take proper directions. Some simple assumptions have been made for this analysis, based on the interviews with SMEs:

- $20 \%$ of the swarfs amount is irrecoverable

- Operator average wage: 35.000 Euros per year

- Mini-Factory annual production; about 50 tons.

- Overheads: about $20 \%$ of total costs.

Due to the significant space renting costs and management of small pieces of furniture, disposal of scraps is the most convenient policy for low level of scraps, rather than reusing or selling back swarfs, thanks to the low loss of recoverable material compared to management and warehousing costs.

The delivery process is extremely "lean", different solutions have been analyzed and a SWOT analysis (see table 1) has been carried out accordingly; it has been designed only a small area for storing finished products, which is intended to contain a quantity of orders equal to an average daily production stock plus a safety stock. End users may decide to pick up their own furniture by themselves or, alternatively, they may rely on an external courier at an average extra charge of $7 \%$ on sale price (within a range of $100 \mathrm{~km}$ ), according to interviews with woodworker SMEs. In house solution may represent an alternative for great volumes.

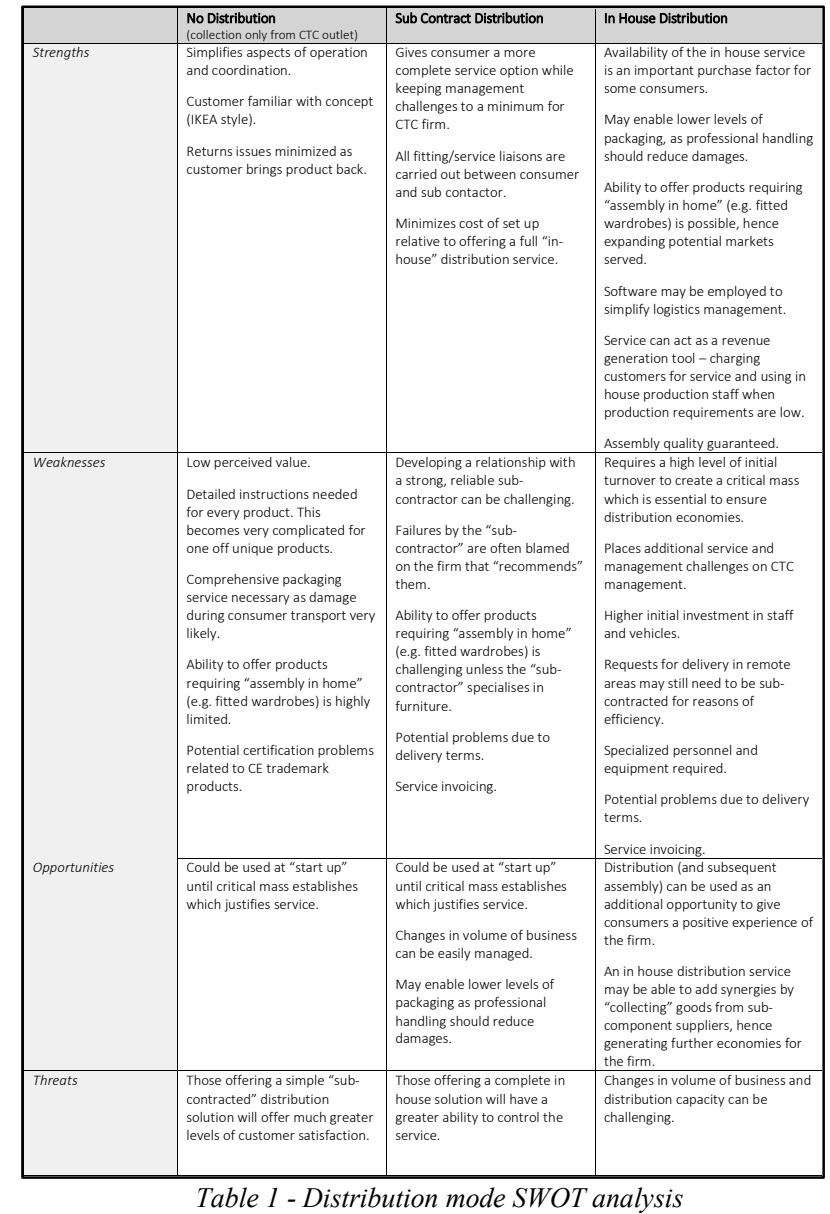

\section{Organizational model and ICT tools}

Working within a mall means that employees performing work affecting either the product or the service delivered by the Mini-Factory shall be complying with the shopping center requirements; moreover, they must be competent on the basis of appropriate education, training, skills and experience.

The main roles of a Mini-Factory have been identified as follows [14]:

- CNC Operators, who essentially take care of operations.

- Shop Operators, who represent the interface to the Customers on the front desk; they are responsible for managing the production scheduling

- Manager, who is responsible for the Mini-Factory organization and for the profit center.

Due to high availability of panel wholesalers and from interviews with Woodworkers, it was determined that a limited warehouse is necessary for a Mini-Factory, to contain 2-3 days production panels and relevant accessories.

A proposal for a rational layout has been developed as a result of workspace minimization, thus reducing unintended material transfer.

Both layout and warehouse should be reviewed in 
compliance with the shopping mall requirements and policies.

As far as ICT is concerned, the following tools are needed to properly support the PSM: a Scheduler, a Supply Chain Manager and an Inventory Manager.

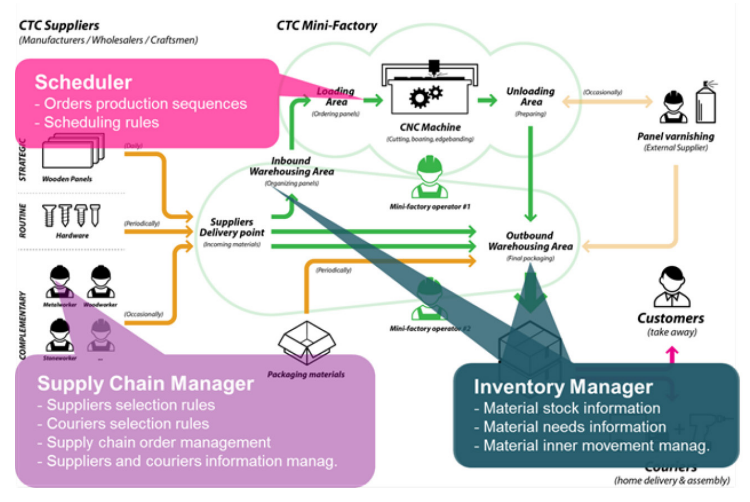

Figure 2- ICT tools

Different ICT tools are available on the market and the software selection is out of scope as far as this paper is concerned. Nevertheless, typical features have been determined, to identify an open source tool, which could prove to be as flexible as it is required by a Mini-Factory [15].

To identify the specific management software a two steps analysis has been performed, dealing with non functional and functional requirements [17]. In the first stage, several ERP open source software has been analyzed by considering functional requirements to be ensured to let the Mini factory works. Then the small numbers of open source software able to cover the majority of the functional requirements have been evaluated on the basis of four non functional criteria:

- Flexibility, adapting the software to the needs of a company, flexibility also implies issues such as ease of use, management and platforms independency.

- Support, infrastructure and documents available for the user.

- Continuity, guarantees that the project is not abandoned, and in case it is, the organization IT team is able to continue developing it according to the need of the company

- Maturity, related with the development stage of the software and the amount of available references on experiences.

In conclusion, for its small size and the reduced complexity of the operations, flexibility Mini factory ICT structure is extremely simplified compared with a traditional business. Indeed, all the Mini factory activities can be easily managed with three small software tools: a configurator, an freeware ERP and a freeware production scheduler.

\section{MINI-FACTORY NETWORK}

The production system model of a CTC Mini-Factory can be extended setting-up a scenario characterized by a network of Mini-Factories distributed in a region or in a country. The network concept needs a second-tier organization Macrofactory for supporting coordination among Mini-Factories and exploiting economies of scale in some activities [18] [19]. The Macro-Factory is both a physical and an organizational entity that provides vital support and information to several MiniFactories, without participating in the manufacturing activities. It is mainly conceived and intended for support activities, such as: long-term planning and forecasting, order management, contracts with suppliers, maintenance, technical support, installations, logistics, etc. Single Mini-Factories can access to these shared activities, thus exploiting economies of scale.

The introduction of this second level reduces the activity in charge of single Mini-Factories, thus focusing resources on higher added value tasks, such as the CRM (Customer Relationship Management) and the Customer oriented processes. The consequent reduction of the processes those are locally implemented, positively affects the standardization of the business model; in other words, the simplification of the Mini-Factory model increases the repeatability level and effectiveness of the process instantiation. Finally, with reference to the business model of a single Mini-Factory, procurement, transport, human resources management, and supervision-coordination activities could be centralized in the Macro-factory (Fig.3).

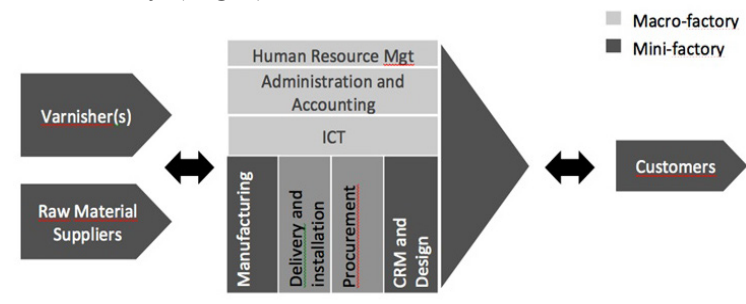

Figure 3-Macro-Factory activities

\section{CONCLUSION \& FUTURE RESEARCH}

The definition of a Mini-Factory Production System Model (i.e. PSM), as presented in the state of the art literature, has been reviewed and integrated, to provide SMEs with a business model as a close as possible to Customers, in terms of product design, quality and delivery time.

Core processes and development choices have been discussed together with requirements for organizational aspects and ICT tools.

Strategic, tactic and operational results have been dealt with, thus highlighting the opportunities for a stand alone MiniFactory and the synergies provided by a network of MiniFactories coordinated by a Macro-factory.

Finally, the PSM might be extended to further industrial sectors, providing that regulation, technological, environmental and social issues are properly coped with [20, 21].

\section{ACKNOWLEDGEMENTS}

The work presented here is part of the project "CTC- Close To Customer"; this project has received funding from the European Union's Seventh Framework Programme for research, technological development and demonstration under grant agreement no FoF.NMP.2013-6 608736 - CTC. 


\section{REFERENCES}

[1] Reichwald, R., Stotko, C. M., \& Piller, F. T. (2005). Distributed minifactory networks as a form of real-time enterprise: concept, flexibility potential and case studies. In The Practical Real-Time Enterprise (pp. 403-434). Springer Berlin Heidelberg.

[2] http://ec.europa.eu/eurostat/statisticsexplained/index.php/Manufacture_of_furniture_statistics__NACE_Rev._2

[3] CBI. (2007). The domestic furniture market in the EU

[4] Seregni, M., Opresnik, D., Zanetti, C., Taisch, M., \& Voorhorst, F. (2014). Mini Factory: A Successful Model for European Furniture Industry?. In Advances in Production Management Systems. Innovative and Knowledge-Based Production Management in a Global-Local World (pp. 571-578). Springer Berlin Heidelberg.

[5] Arbeit und Leben Bielefeld e.V. (DGB/VHS) (2009). European Sector Monitor of the wood/furniture industry

[6] Mourtzis, D., \& Doukas, M. (2013). Decentralized manufacturing systems review: challenges and outlook. In Robust Manufacturing Control (pp. 355-369). Springer Berlin Heidelberg.

[7] Kühnle, H. (Ed.). (2009). Distributed manufacturing: paradigm, concepts, solutions and examples. Springer Science \& Business Media.

[8] Piller, F. T. (2002). Economies of interaction and economies of relationship: Value drivers in a customer centric economy (pp. 1-15). Brisbane.

[9] Zäh, M. F., \& Wagner, W. (2003). Planning Mini-Factory Structures for the Close-to-Market Manufacture of Individualized Products. Proceedings of the MCPC, 3.

[10] Wiendahl, H. P., ElMaraghy, H. a., Nyhuis, P., Zäh, M. F., Wiendahl, H. H., Duffie, N., \& Brieke, M. (2007). Changeable Manufacturing Classification, Design and Operation. CIRP Annals - Manufacturing Technology, 56(2), 783-809. http://doi.org/10.1016/j.cirp.2007.10.003

[11] Reichwald, R., Stotko, C. M., Seifert, S., \& TUM-AIB, L. (2003). Internationalizing Mass Customization-Minifactories as a transnational solution. In Proceedings of the 2nd Interdisciplinary World Congress on Mass Customization and Personalization.

[12] http://www.wsj.com/articles/SB10001424052702303417104579543760 893597806

[13] http://p2pfoundation.net/Mass_Customization

[14] Pedrazzoli, P., Cavadini, F. A., Corti, D., Barni, A., \& Luvini, T. (2014). An Innovative Production Paradigm to Offer Customized and Sustainable Wood Furniture Solutions Exploiting the Mini-Factory Concept. In Advances in Production Management Systems. Innovative and Knowledge-Based Production Management in a Global-Local World (pp. 466-473). Springer Berlin Heidelberg.

[15] Wang, S., \& Wang, H. (2014). A Survey of Open Source Enterprise Resource Planning (ERP) Systems. International Journal of Business and Information, $9(1)$.

[16] GORISHTI, A., \& SEVRANI, K. (2012). A survey on Open Source ERP and the reasons for their use by SMEs. International Journal of Science, Innovation \& New Technology.

[17] Benlian, A., \& Hess, T. (2011). Comparing the relative importance of evaluation criteria in proprietary and open-source enterprise application software selection-a conjoint study of ERP and Office systems. Information Systems Journal, 21(6), 503-525

[18] Marcotte, F., Grabot, B., \& Affonso, R. (2009). Cooperation models for supply chain management. International Journal of Logistics Systems and Management, 5(1), 123-153.

[19] Rudberg, M., \& West, B. M. (2008). Global operations strategy: Coordinating manufacturing networks. Omega, 36(1), 91-106.
[20] M. Fiasché, "A quantum-inspired evolutionary algorithm for optimization numerical problems". In LNCS : Vol. 7665, 2012, ICONIP 2012, Part III (pp. 686-693), doi: 10.1007/978-3-642-34487-9_83

[21] M. Fiasché, A.Verma, M. Cuzzola, F.C. Morabito G. Irrera, "Incremental- Adaptive- Knowledge Based- Learning for Informative Rules Extraction in Classification Analysis of aGvHD", IFIP Advances in Information and Communication Technology, Volume 363 AICT, Issue PART 1, 2011, Pages 361-371. DOI: 10.1007/978-3-642-23957141 